\title{
Acerca de la PAAF de mama
}

\section{Sr. Director:}

Son muchas las quejas que en nuestro entorno están surgiendo últimamente en relación al dictamen de "no valorable " con el que los informes citológicos de punciones de mama responden a la petición de estudio por parte de los clínicos. A este respecto queremos hacer una reflexión, la cual tiene carácter de petición.

La punción aspiración con aguja fina, más conocida como PAAF, es un instrumento diagnóstico de primer orden cuya eficacia ha sido sobradamente demostrada y avalada por numerosos estudios. Entre sus ventajas se incluyen la sencillez, la rapidez, la inocuidad y el bajo coste; estas características le confieren un valor inestimable en el proceso diagnóstico de lesiones mamarias ya sean palpables o no palpables. Su valor predictivo positivo es muy alto en manos expertas y aun es mayor si se acompaña de una adecuada concordancia con los hallazgos de la exploración clínica y radiológica (triple test). Asimismo es de sobra conocida la mayor adecuación diagnóstica cuando la persona que realiza la punción es aquella que luego interpreta los frotis, y no debe extrañar esta circunstancia pues a la hora de realizar un diagnóstico citológico los datos clínicos son de suma importancia. En la mama esta necesidad es mayor debido a que lesiones benignas pueden cursar con cierta atipia y viceversa con lo que datos tales como la edad de la paciente, tamaño de la lesión, consistencia, delimitación, adherencia a planos profundos e imagen radiológica ayudan en gran número de ocasiones por inclinar el diagnóstico en una u otra dirección; no en vano es conocida en el mundo citológico la denominada "zona gris", donde se agrupan lesiones de difícil diagnóstico que no es prudente asignar a priori a uno de los grupos diagnósticos y que en última instancia requerirán una confirmación histológica. Ante esta situación son muchos los centros que han optado por recurrir a la biopsia con aguja gruesa (tru-cut) en sustitución de la PAAF, olvidando a nuestro juicio los valores que precisamente caracterizan a esta última si bien consiguiendo un criterio arquitectural sólo presente en la primera.

Lamentablemente y debido a motivos del todo heterogéneos no son pocos los centros donde el prosector es un clínico, persona que observa y estudia macroscópicamente la lesión. En cambio es el citólogo el profesional sobre el que recae la responsabilidad de realizar un diagnóstico muchas veces no amparado por una adecuada información acerca de la lesión problema.

En nuestra opinión, y por supuesto de manera general, las peticiones cursadas por los clínicos no se remiten adecuadamente cumplimentadas privando de esta forma al citólogo de una información crucial. Esta información a veces es incluso necesaria para valorar la adecuación de la muestra por lo que en último término es responsable del ya citado diagnóstico de "material no valorable".

Como conclusión y desde nuestra posición de citólogos rogamos a todos aquellos que crean como nosotros en las ventajas de la PAAF, una reflexión y un mínimo esfuerzo pues con aportar escasos datos físicos y radiológicos se puede cumplimentar un triple test de gran beneficio para el citólogo y lo que es más importante, para la paciente.

F. J. Torres Gómez Servicio de Anatomía Patológica del Hospital Punta de Europa Algeciras (Cádiz)

Correspondencia: Dr. F. J. Torres Gómez Plaza de la Encarnación, 32 - p1, 2B E 41003 Sevilla javiertorresgomez@yahoo.es 